\title{
Herança de caracteres morfológicos de grãos primários em aveia ${ }^{(1)}$
}

\author{
Cândida Braga Cabral(2), Sandra Cristina Kothe Milach $^{(2)}$, Marcelo Teixeira Pacheco ${ }^{(2)}$ e Leonardo Araripe Crancio(3)
}

\begin{abstract}
Resumo - A produção de cultivares com grãos de superior qualidade física tem adquirido importância, especialmente com a crescente globalização dos mercados sul-americanos. A fim de definir as melhores estratégias de ação para o melhoramento dessas características, é fundamental o estudo das suas bases genéticas e, até o momento, não existe registro de trabalhos desta natureza com germoplasma brasileiro de aveia. Este trabalho foi realizado com o objetivo de estimar o modo de herança e herdabilidade dos caracteres área, comprimento, largura e perímetro de grãos primários de aveia. Foram avaliadas amostras de 20 grãos de um número variável de plantas para as gerações $\mathrm{P}_{1}, \mathrm{P}_{2}, \mathrm{~F}_{1}, \mathrm{~F}_{2} \mathrm{e}$ $\mathrm{F}_{3}$ de cinco cruzamentos de aveia através da análise de imagens digitalizadas. Com esses dados, foram obtidas as distribuições de freqüência e variâncias, e estimados os valores de herdabilidade no sentido amplo e pai-progênie, bem como os efeitos gênicos predominantes. Os resultados obtidos mostraram que existe variabilidade em progênies precoces em relação às características de grão avaliadas, e que aditividade e dominância são os efeitos gênicos que estão atuando. Não foi detectada a presença de genes maiores atuando na expressão dessas características. Aliadas a isso, as variações contínuas em $\mathrm{F}_{2}$ indicam que seleção amena deve ser aplicada em gerações iniciais.
\end{abstract}

Termos para indexação: Avena sativa, variação genética, herdabilidade.

\section{Inheritance of primary grain morphology traits in oat}

\begin{abstract}
The production of varieties with higher grain physical quality has acquired importance, especially with the globalization of the South American markets. In order to define the best strategies for the improvement of these traits, it is important to study their genetic basis, and until now, studies of this nature have not been conducted with Brazilian oat genotypes. This work was carried out with the objective of determining the inheritance and heritability of the area, length, width and perimeter of primary oat grains. Samples of 20 grains of a variable number of plants from the generations $\mathrm{P}_{1}, \mathrm{P}_{2}, \mathrm{~F}_{1}$, $\mathrm{F}_{2}$ e $\mathrm{F}_{3}$ from five crosses were evaluated through analysis of digitalized images. From these data frequency distributions and variances were obtained and heritability values were estimated in broad sense and parent offspring, as well as the predominant gene effects. The results showed that there is variability in early generations for the grain traits evaluated and that additivity and dominance are the main gene effects acting. The presence of major genes was not detected in the expression of these traits, and continuous variation in the $\mathrm{F}_{2}$ indicates that low selection pressure has to be applied in early generations.
\end{abstract}

Index terms: Avena sativa, genetic variation, heritability.

(1) Aceito para publicação em 18 de outubro de 2000.

Extraído da Dissertação de Mestrado apresentada pelo primeiro autor à Universidade Federal do Rio Grande do Sul (UFRGS), Porto Alegre, RS.

(2)UFRGS, Dep. de Plantas de Lavoura, Caixa Postal 776, CEP 91501-970 Porto Alegre, RS. E-mail: cbcabral@ig.com.br, milach@vortex.ufrgs.br, marpac@vortex.ufrgs.br

(3)UFRGS, Faculdade de Agronomia. Bolsista PIBIC-CNPq.

\section{Introdução}

Na América Latina, o Brasil se destaca como o país de maior produção de aveia (Avena sativa L.). As condições climáticas do sul do Brasil permitem o cultivo de duas culturas ao ano, e a aveia tem sido o cereal mais apto a participar do sistema de rotação 
de culturas, devido às suas propriedades recuperadoras do solo (Federizzi et al., 1995).

Os programas de melhoramento do sul do Brasil têm produzido com sucesso cultivares de alto potencial de rendimento de grãos, porte baixo e precoces (Federizzi et al., 1991). Contudo, a produção de cultivares com qualidade física e química superior de grão tem adquirido importância, especialmente com a tendência à globalização dos mercados sul-americanos.

A qualidade morfológica do grão refere-se a grãos bem desenvolvidos e de tamanho uniforme. Comprimento e largura são as duas medidas básicas que podem definir o tamanho do grão. Sapirstein (1995) define o comprimento como sendo o maior eixo longitudinal do grão e a largura o maior eixo perpendicular ao comprimento. Contudo, devido à dificuldade de avaliação dessas características, o peso do hectolitro e o peso de mil grãos têm sido amplamente utilizados na avaliação da qualidade morfológica do grão e do rendimento industrial de aveia, embora Pixley \& Frey (1991) tenham relatado que nem sempre essas medidas estão positivamente correlacionadas com a qualidade morfológica do grão.

Até algum tempo, os componentes de qualidade morfológica do grão não eram estudados, devido à dificuldade de obtenção de dados. As medidas eram feitas por meio de paquímetros (Floss et al., 1996) ou da projeção de sombras dos grãos sobre papel milimetrado (Murphy \& Frey, 1962), processos demorados e de pouca precisão. Com o desenvolvimento da análise de imagens digitalizadas (AID), hoje é possível avaliar caracteres morfológicos do grão com alta precisão. A imagem captada por uma vídeocâmera e transferida para o computador é analisada com um programa de computador que possibilita a realização de uma série de medidas (Bothona, 1997). Shatadal et al. (1995) compararam classificações manuais e através de AID de grãos de trigo, cevada, aveia e arroz, e concluíram que essa técnica possibilita detectar pequenas diferenças que não são obtidas através de classificação manual. Godoy et al. (1994) demonstraram que não houve diferença significativa para os dados de largura e comprimento de grão, quando obtidos através de AID ou de medições com paquímetro.

Milach et al. (1996), por meio de AID, caracterizaram diferentes cultivares de aveia quanto a caracteres morfológicos de grão, e observaram que as cultivares mais recentes apresentam grãos maiores, o que indica que seleção de cultivares com alto rendimento e peso do hectolitro, atua diretamente na qualidade morfológica do grão.

A qualidade morfológica do grão é uma característica complexa, e por isso seu estudo vem sendo realizado por meio dos componentes envolvidos (Bothona, 1997; Bothona et al., 1999). Prasad \& Seetharaman (1991) identificaram três genes responsáveis pelo comprimento e formato do grão em arroz. Backes et al. (1995) obtiveram estimativas altas de herdabilidade para comprimento $(0,81)$ e largura do grão $(0,88)$ em cevada. Quisenberry (1926), citado por Marshall \& Shaner (1992), concluiu em seus estudos que o comprimento de grãos é controlado por três pares de genes em aveia. Torrie (1939), citado por Marshall \& Shaner (1992), observou que a relação comprimento/largura do grão é controlada por dois pares de genes. Murphy \& Frey (1962) encontraram valores de herdabilidade de 0,51 para o comprimento e de 0,35 para largura do grão. Os autores atribuíram os semelhantes valores de herdabilidade desses dois caracteres ao fato de que a largura, assim como o peso dos grãos, é definida até três semanas após a antese, estando sujeita a maior efeito do ambiente, enquanto o comprimento do grão é definido ao redor de oito dias após a antese em aveia. Em trigo, o comprimento do grão também é definido em menor período de tempo, 10 dias após a antese (Lernsten, 1987). Os autores ainda encontraram o indicativo de que esses caracteres são herdados quantitativamente, uma vez que as distribuições de freqüência foram próximas da normalidade nos 12 cruzamentos de aveia estudados.

Bothona et al. (1999) caracterizaram diferentes genótipos de aveia dos programas de melhoramento de aveia do sul do Brasil, quanto a aspectos de qualidade física do grão, procurando identificar o padrão de grão específico de cada um através da análise de imagens digitalizadas. Estes autores identificaram variabilidade para componentes de qualidade física do grão entre os genótipos avaliados e um padrão de qualidade física do grão específico para cada genótipo. Também, que o tamanho de grão pode ser determinado pela avaliação da área do grão com casca, bem como medidas de comprimento e largura são 
necessárias para determinar o formato e o tipo específico de grão de um genótipo. No entanto, estudos genéticos sobre essas características em genótipos brasileiros de aveia ainda não foram relatados.

Este trabalho teve por objetivo estimar o modo de herança e herdabilidade dos caracteres área, comprimento, largura e perímetro de grãos de aveia.

\section{Material e Métodos}

Foram utilizados quatro genótipos de aveia, sendo três cultivares elite do Programa de Melhoramento Genético de Aveia da UFRGS, e o outro, uma cultivar elite proveniente de outro programa (Tabela 1). Estes genótipos foram selecionados com base numa análise de dados de peso de mil grãos (PMG) e peso do hectolitro (PH) obtidos dos Ensaios Sul-brasileiro e de Cultivares Recomendadas de 1995 (Federizzi et al., 1996a, 1996b; Floss et al., 1996).

Nos anos de 1995, 1996 e 1997 foram realizados cinco cruzamentos entre esses genótipos, e os híbridos, cultivados para obtenção de sementes nas gerações $F_{1}, F_{2}$ e $F_{3}$.

Em 1998, um experimento contendo os genitores e gerações $F_{1}, F_{2}$ e $F_{3}$, foi conduzido na Estação Experimental Agronômica da UFRGS (EEA/UFRGS) em Eldorado do Sul, RS. Esta região está situada na região fisiográfica da Depressão Central, a 30 ${ }^{\circ}{ }^{\prime} 52^{\prime \prime}$ de latitude sul e 51'039'8" de longitude oeste, com altitude média de $46 \mathrm{~m}$ acima do nível do mar. O solo pertence à Unidade de Mapeamento São Jerônimo, classificado como Podzólico VermelhoEscuro. O clima da região é do tipo Cfa, subtropical úmido, com chuvas bem distribuídas durante o ano, de acordo com a classificação de Köppen aplicada ao estado por Moreno (1961).

A fertilidade foi corrigida conforme análise do solo e recomendações da Rede Oficial de Laboratórios de Análise do Solo (ROLAS). Durante a condução do experimento no campo, foram adotadas as técnicas culturais recomendadas para a cultura da aveia, visando a eliminação de ervas daninhas e redução da incidência de pragas, moléstias fúngicas e insetos.

O delineamento experimental foi de blocos completamente casualizados, sendo cada planta uma unidade experimental e o número de plantas variando de acordo com a geração e o cruzamento avaliado. A semeadura foi manual, feita em 29 de maio de 1998. As parcelas das gerações $\mathrm{P}_{1}$ e $\mathrm{P}_{2}$ foram constituídas de duas linhas de cada pai, cada linha com $3 \mathrm{~m}$ de comprimento, com espaçamento de $0,20 \mathrm{~m}$ entre linhas, e $0,15 \mathrm{~m}$ entre plantas, distribuídas ao longo dos blocos. As gerações $\mathrm{F}_{2}$ e $\mathrm{F}_{3}$ diferiram dos pais somente no número de linhas, que foram 15 por população $\mathrm{F}_{2}$, e uma linha $\mathrm{F}_{3}$ por planta $\mathrm{F}_{2}$ colhida em 1997. Quanto à $\mathrm{F}_{1}$, conforme o número de sementes foram semeadas duas linhas, com um espaçamento entre plantas de $0,30 \mathrm{~m}$ e o entre linhas idem aos demais. A adubação nitrogenada foi aplicada na forma de uréia, em duas épocas, entre a emergência da $3 \underline{a}$ e 4 a folhas e entre a emergência da $6 \underline{a}$ e 7 a folhas.

As plantas foram acompanhadas durante o ciclo de desenvolvimento, e no florescimento foi realizada a marcação da panícula principal, por meio de fita adesiva. A panícula principal de cada planta foi colhida separadamente por ocasião da maturação e mantida em câmara fria a $10^{\circ} \mathrm{C}$ na EEA/UFRGS até o momento de utilização. Foram coletadas 30 panículas de cada pai, e entre 65 e 118 panículas nas populações $\mathrm{F}_{2}$ dos cruzamentos UFRGS $7 \mathrm{x}$ UFRGS 14, UFRGS 7 x UFRGS 17, UFRGS $14 \times$ UFRGS 17, UFRGS 7 x CTC 3 e UFRGS 14 x CTC 3 . Das gerações $\mathrm{F}_{3}$, foram coletadas de oito a dez panículas por linha, e utilizadas aproximadamente 60 linhas de cada população dos cruzamentos entre UFRGS 7 x UFRGS 14, UFRGS 7 x UFRGS 17 e UFRGS 14 x UFRGS 17. Posteriormente, cada panícula principal foi debulhada manualmente, e foram separados 20 grãos primários da metade superior da panícula. Os trabalhos de debulha, captação e posterior análise de imagens do material foram realizados nas instalações do Departamento de Plantas de Lavoura da Faculdade de Agronomia da Universidade Federal do Rio Grande do Sul.

Tabela 1. Genótipos de aveia utilizados no estudo, suas respectivas genealogias, peso de mil grãos (PMG) e peso do hectolitro $(\mathrm{PH})$.

\begin{tabular}{llcc}
\hline Genótipo & Genealogia & $\mathrm{PMG}^{(1)}$ & $\mathrm{PH}^{(2)}$ \\
\hline UFRGS 7 & $\mathrm{X} 1205 / \mathrm{FLA} 1093$ & $\mathrm{~B}$ & $\mathrm{~B}$ \\
UFRGS 14 & $805165 / / \mathrm{COR}^{2} / \mathrm{CTZ}^{3} /$ Pendek/ ME 1563 & $\mathrm{~A}$ & $\mathrm{I}$ \\
UFRGS 17 & $\mathrm{COR}^{2} / \mathrm{CTZ}^{3} / \mathrm{Pendek}^{2} \mathrm{ME} 1563 / / 76-29 / 76-23$ & $\mathrm{I}$ & $\mathrm{A}$ \\
CTC 3 & Steele//Coronado $/ \mathrm{Cortez}^{3} /$ Pendek/ ME 1563 & $\mathrm{I}$ & $\mathrm{A}$ \\
\hline
\end{tabular}

(1) A (alto): acima de $30 \mathrm{~g}$; I (intermediário): de 25 a $30 \mathrm{~g}$; B (baixo): abaixo de $25 \mathrm{~g}$ (desaristado). (2) $\mathrm{A}$ (alto): acima de $45 \mathrm{~kg} / \mathrm{hL}$; I (intermediário): de 40 a $45 \mathrm{~kg} / \mathrm{hL}$; B (baixo): abaixo de $40 \mathrm{~kg} / \mathrm{hL}$ (desaristado). Fonte: Bothona (1997). 
As amostras de grãos primários foram submetidas à análise de imagens digitalizadas para obtenção de dados das seguintes características morfológicas de grãos de cada genótipo parental e gerações segregantes: área $\left(\mathrm{mm}^{2}\right)$; comprimento, largura e perímetro $(\mathrm{mm})$. As imagens de grão foram captadas por vídeo-câmera e transferidas para um computador mediante uma placa de vídeo externa. Após a captação de imagens, as amostras foram analisadas com o programa SIGMA SCAN/IMAGE 1.2. Foi utilizado um quadrado de papel de tamanho padronizado $\left(1 \mathrm{~cm}^{2}\right)$ presente em todas as imagens para a conversão dos dados de pixels para milímetros.

Foram realizadas a análise de variância e a comparação de médias pelo teste de Duncan $(\alpha=0,05)$ de todos os caracteres avaliados.

Para estudo da herança desses componentes de grãos primários em aveia e estimativa dos efeitos gênicos, foram analisadas as distribuições de freqüência e obtidas as estimativas das médias e variâncias, e determinados os valores de herdabilidade no sentido amplo $\left(\mathrm{h}^{2} \mathrm{a}\right)$ e pai-progênie (b), que mais se aproxima do sentido restrito.

As distribuições de freqüência das gerações $\mathrm{P}_{1}, \mathrm{P}_{2}$ e $\mathrm{F}_{2}$ em cada um dos cruzamentos avaliados foram obtidas pelo agrupamento dos dados em classes. Os intervalos de classe foram estabelecidos com base no desvio-padrão médio de cada caráter, de acordo com Steel \& Torrie (1980).

A estimativa dos efeitos gênicos foi realizada, relativamente aos cruzamentos UFRGS 7 x UFRGS 14, UFRGS 7 x UFRGS 17 e UFRGS 14 x UFRGS 17, pelo método "teste de escala conjunto" proposto por Cavalli (1952) citado por Mather \& Jinks (1982). O método consiste em estimar os parâmetros média (m), aditividade (a) e dominância (d) a partir das médias e variâncias das gerações disponíveis, seguido da comparação, pelo qui-quadrado $\left(\chi^{2}\right)$, entre as médias das gerações observadas e estimadas. Para estimativa da ação gênica foi considerado:

$\overline{\mathrm{P}}_{1}=\mathrm{m}+\mathrm{a}+\mathrm{i}$,

$\overline{\mathrm{P}}_{2}=\mathrm{m}-\mathrm{a}+\mathrm{i}$,

$\overline{\mathrm{F}}_{1}=\mathrm{m}+\mathrm{d}$,

$\overline{\mathrm{F}}_{2}=\mathrm{m}+(1 / 2) \mathrm{d}, \mathrm{e}$

$\overline{\mathrm{F}}_{3}=\mathrm{m}+(1 / 4) \mathrm{d}$,

onde: $\mathrm{P}_{1}, \mathrm{P}_{2}, \mathrm{~F}_{1}, \mathrm{~F}_{2}$ e $\mathrm{F}_{3}$ representam a média de cada geração; $\mathrm{m}$ é a média geral; a é o efeito de aditividade, $\mathrm{d}$ é $\mathrm{o}$ efeito de dominância, e i, o efeito epistático de aditividade $\mathrm{x}$ aditividade.

Em dois desses cruzamentos (UFRGS 7 x UFRGS 14 e UFRGS 14 x UFRGS 17), foi testado o modelo de três parâmetros, devido à disponibilidade de quatro gerações, e no cruzamento restante, com cinco gerações, foi testado o modelo com quatro parâmetros, uma vez que o método do "teste de escala conjunto" permite estimar um número de parâmetros inferior em uma unidade ao número de gerações disponíveis, de modo que o teste de adequação do modelo possa ser feito pelo qui-quadrado. A significância dos efeitos estimados pelo método "teste de escala conjunto" foi efetuada usando-se o teste t.

As variâncias de cada caráter foram estimadas em cinco cruzamentos conforme proposto por Allard (1960):

$\mathrm{VP}=\mathrm{VF}_{2}$,

$\mathrm{VE}=\left(\mathrm{VP}_{1}+\mathrm{VP}_{2}\right) / 2, \mathrm{e}$

$\mathrm{VG}=\mathrm{VP}-\mathrm{VE}$,

onde: $\mathrm{VP}_{1}, \mathrm{VP}_{2}, \mathrm{eVF}_{2}$ representam as variâncias das gerações $\mathrm{P}_{1}, \mathrm{P}_{2}$, e $\mathrm{F}_{2}$, respectivamente, sendo que, VP, VE e VG representam as variâncias fenotípica, ambiental e genética, respectivamente.

As estimativas de herdabilidade no sentido amplo $\left(\mathrm{h}^{2}{ }_{\mathrm{a}}\right)$ e pai-progênie (b) foram calculadas segundo as seguintes equações:

$\mathrm{h}^{2}{ }_{\mathrm{a}}=(\mathrm{VP}-\mathrm{VE}) / \mathrm{VP}$ (Allard, 1960), e $\mathrm{b}=$ covariância $\left(\mathrm{F}_{2} \mathrm{~F}_{3}\right) / \mathrm{varF}_{2}$ (Borém, 1997).

Nas estimativas de $\mathrm{h}_{\mathrm{a}}{ }_{\mathrm{a}}$, foram utilizadas as gerações $\mathrm{P}_{1}, \mathrm{P}_{2}$ e $\mathrm{F}_{2}$, semeadas no campo no ano de 1998. Já para o cálculo da herdabilidade pai-progênie, foram utilizadas a geração $F_{2}$ colocadas no campo em 1997 e suas respectivas progênies, linhas $F_{3}$ de 1998.

\section{Resultados e Discussão}

Diferenças significativas foram observadas entre as médias dos genitores, indicando existir variabilidade entre os pais para as características área, comprimento, largura e perímetro de grãos primários em aveia (Tabela 2). Apesar da formação de mais grupos pelo teste de comparação de médias, os genitores podem ser divididos em dois grupos distintos: um, formado por UFRGS 7, com baixos valores de todas as características; e o grupo de valores intermediários a altos, constituído por CTC 3, UFRGS 14 e UFRGS 17, como ficou evidenciado pelas distribuições de freqüência, onde houve sobreposição das curvas dos genitores deste segundo grupo na maioria das características, em maior ou menor grau, conforme a característica em questão (Figuras 1 a 4). A variabilidade entre genitores observada neste trabalho está de acordo com a observada por Bothona et al. (1999).

A análise das distribuições de freqüência evidenciou que as características analisadas são de herança quantitativa, pois a geração $F_{2}$ apresentou variação contínua em todos os cruzamentos (Figuras 1 a 4). 
Esses dados confirmam os resultados obtidos por Murphy \& Frey (1962) quanto às características comprimento e largura. Por outro lado, contrariam a conclusão de Quisenberry (1926) citado por Marshall \& Shaner (1992) de que o comprimento de grãos em aveia é controlado por três pares de genes. Da mesma forma que Prasad \& Seetharaman (1991) identificaram três genes responsáveis pelo comprimento do grão em arroz.

Não foi observada segregação transgressiva significativa na geração $F_{2}$ dos cruzamentos avaliados, provavelmente porque os genes favoráveis ou desfavoráveis controlando essas características não estão distribuídos de forma complementar entre os genitores. Exceção foi observada no cruzamento UFRGS 7 x CTC 3 para largura de grão, onde parece ter havido um acúmulo de genes para redução da característica em progênies $\mathrm{F}_{2}$. Em relação aos caracteres comprimento e perímetro, a geração $F_{2}$ foi intermediária ou tendeu ao genitor superior. Nos outros dois caracteres avaliados, área e largura, a $F_{2}$ tendeu para o genitor de menor tamanho ou foi intermediária. Isso se confirma com a análise de média de gerações (Tabela 3), onde a dominância só não foi significativa nos cruzamentos UFRGS $7 \mathrm{x}$ UFRGS 17 em área, e UFRGS 14 x UFRGS 17 para largura e perímetro de grãos primários, tendo havido dominância negativa para área e largura do grão, e positiva nos demais.

Quanto aos efeitos gênicos calculados das quatro características em três populações (Tabela 3), os modelos de três e quatro parâmetros foram aceitos com alta probabilidade, indicando que explicam satisfatoriamente a variação nessas características.

De maneira geral, quando significativo, o parâmetro dominância apresentou maior valor, em módulo, em relação ao parâmetro aditividade, em todas as populações analisadas, como demonstrado pelo valor superior à unidade do grau de dominância (d/a) na Tabela 3, exceção para área, largura e perímetro de UFRGS 7 x UFRGS 14. Por outro lado, embora o efeito de aditividade não tenha sido predominantemente o mais importante, foi significativo em todos os cruzamentos, para todas as características avaliadas, indicando sua atuação na definição dessas características.

No que diz respeito aos efeitos epistáticos, o parâmetro aditividade $\mathrm{x}$ aditividade testado no cruzamento UFRGS 7 x UFRGS 17 não foi significativo em nenhum dos caracteres, indicando que este efeito não está atuando sobre elas apesar do modelo de quatro parâmetros ser significativo.

Quanto às estimativas de variância (Tabela 4), em todos os caracteres, de maneira geral, a variância genética foi superior ou equivalente à variância, devido aos efeitos de ambiente. Exceção ocorreu no cruzamento UFRGS 14 x UFRGS 17, onde a variância ambiental representou $92 \%, 64 \%, 67 \%$ e $70 \%$ da variância fenotípica total para área, comprimento, largura e perímetro dos grãos, respectivamente. O mesmo foi observado no cruzamento UFRGS $14 \mathrm{x}$ CTC 3 com relação à área e largura dos grãos, onde a variância ambiental representou $53 \%$ e $68 \%$ da variação fenotípica, respectivamente.

As estimativas obtidas para os valores de herdabilidade no sentido amplo apresentaram magnitude variável em todos os caracteres avaliados (Tabela 4); na média, os valores foram de 52\% para área, $69 \%$ para comprimento, $52 \%$ para largura e $68 \%$ para perímetro. O cruzamento UFRGS 14 x UFRGS 17 apresentou os menores valores em todas as características morfológicas de grão analisadas neste estu-

Tabela 2. Médias dos caracteres área, comprimento, largura e perímetro de grãos primários, dos genótipos de aveia utilizados como genitores das populações analisadas. EEA/UFRGS, $1998^{(1)}$.

\begin{tabular}{lcccc}
\hline Genitor & $\begin{array}{c}\text { Área } \\
\left(\mathrm{mm}^{2}\right)\end{array}$ & $\begin{array}{c}\text { Comprimento } \\
(\mathrm{mm})\end{array}$ & $\begin{array}{c}\text { Largura } \\
(\mathrm{mm})\end{array}$ & $\begin{array}{c}\text { Perímetro } \\
(\mathrm{mm})\end{array}$ \\
\hline UFRGS 14 & $35,18 \mathrm{~A}$ & $14,41 \mathrm{~A}$ & $3,21 \mathrm{~A}$ & $32,48 \mathrm{~A}$ \\
UFRGS 17 & $32,34 \mathrm{~B}$ & $14,21 \mathrm{~A}$ & $2,89 \mathrm{~B}$ & $31,84 \mathrm{~B}$ \\
CTC 3 & $29,29 \mathrm{C}$ & $13,42 \mathrm{~B}$ & $2,74 \mathrm{C}$ & $30,13 \mathrm{C}$ \\
UFRGS 7 & $24,95 \mathrm{D}$ & $11,41 \mathrm{C}$ & $2,61 \mathrm{D}$ & $26,05 \mathrm{D}$ \\
\hline
\end{tabular}

(1)Médias seguidas de mesma letra não diferem entre si a 5\% de probabilidade, pelo teste Duncan. 

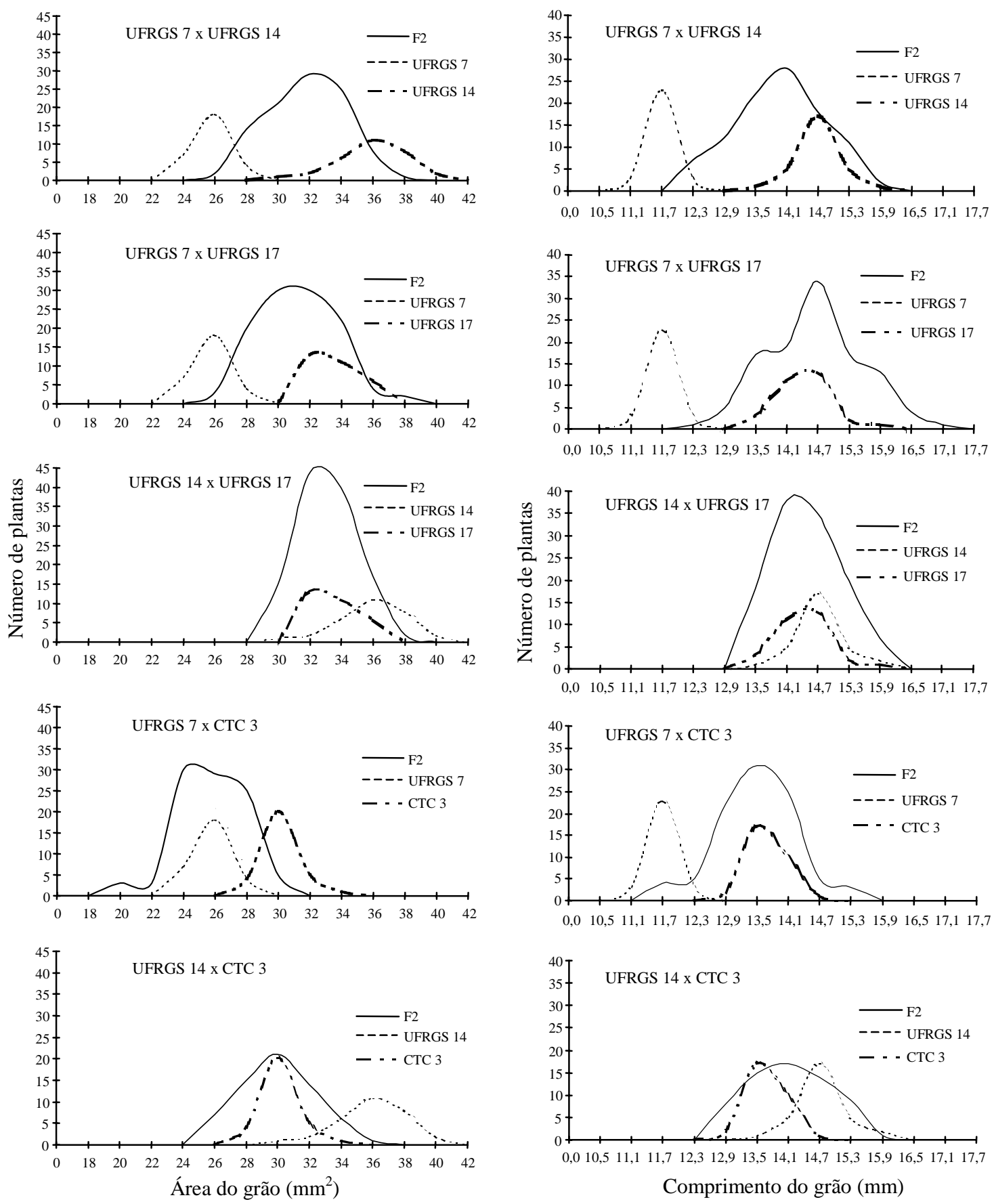

Figura 1. Distribuições de freqüência do caráter área de grãos primários em duas gerações fixas $\left(\mathrm{P}_{1}\right.$ e $\left.\mathrm{P}_{2}\right)$, e uma geração segregante $\left(\mathrm{F}_{2}\right)$, de cinco cruzamentos de aveia. EEA/UFRGS, 1998.

Figura 2. Distribuições de freqüência do caráter comprimento de grãos primários em duas gerações fixas $\left(\mathrm{P}_{1} \mathrm{e}\right.$ $\left.\mathrm{P}_{2}\right)$, e uma geração segregante $\left(\mathrm{F}_{2}\right)$, em cinco cruzamentos de aveia. EEA/UFRGS, 1998. 
do, o que confirma a similaridade genética entre esses genótipos. Os maiores valores também se concentraram em um cruzamento, UFRGS 7 x CTC 3, com exceção da largura onde o cruzamento
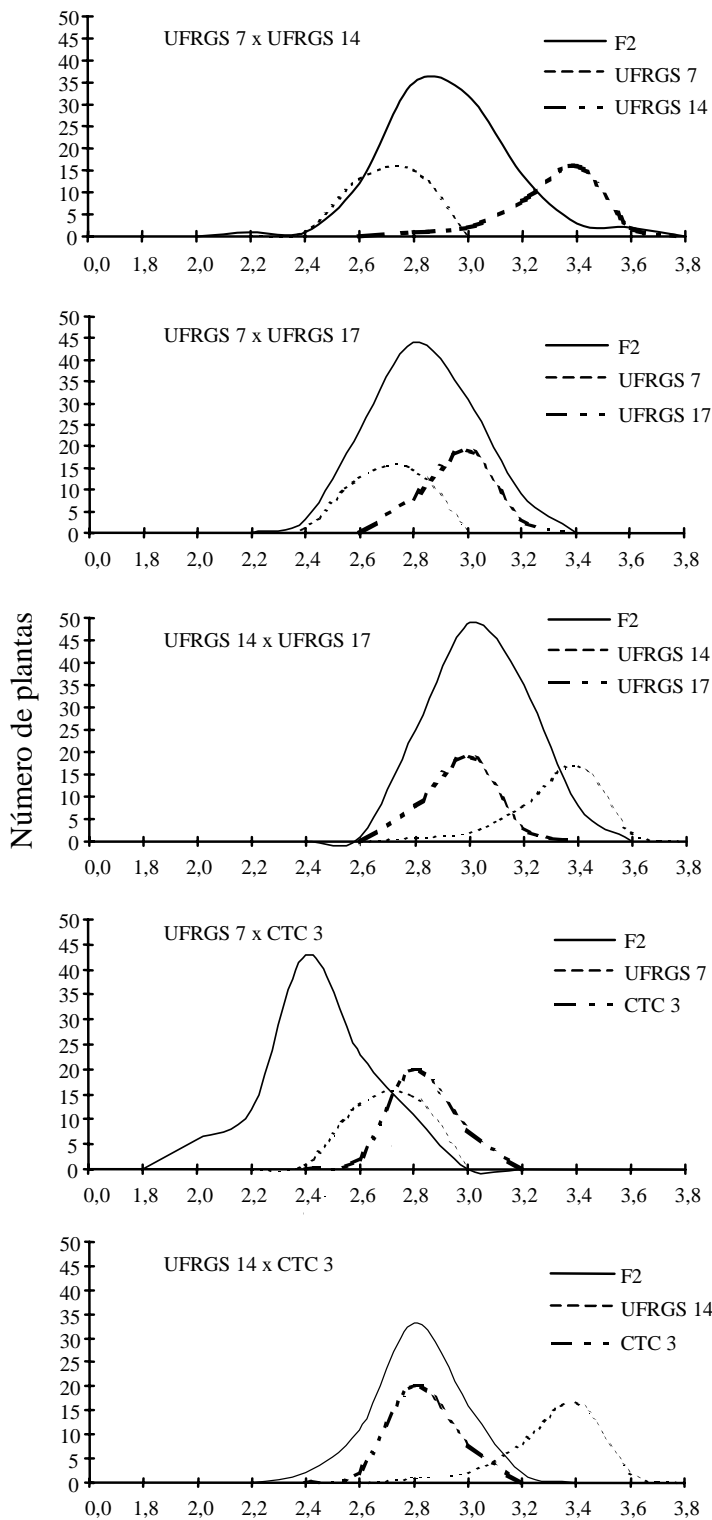

Largura do grão (mm)

Figura 3. Distribuições de freqüência do caráter largura de grãos primários em duas gerações fixas $\left(\mathrm{P}_{1} \mathrm{e} \mathrm{P}_{2}\right)$, e uma geração segregante $\left(\mathrm{F}_{2}\right)$, em cinco cruzamentos de aveia. EEA/UFRGS, 1998.
UFRGS 7 x UFRGS 17 apresentou o maior valor $(69,1 \%)$, seguido por UFRGS 7 x CTC $3(65,4 \%)$.

Segundo as estimativas de herdabilidade no sentido amplo, obtidas em cada cruzamento, a popula-
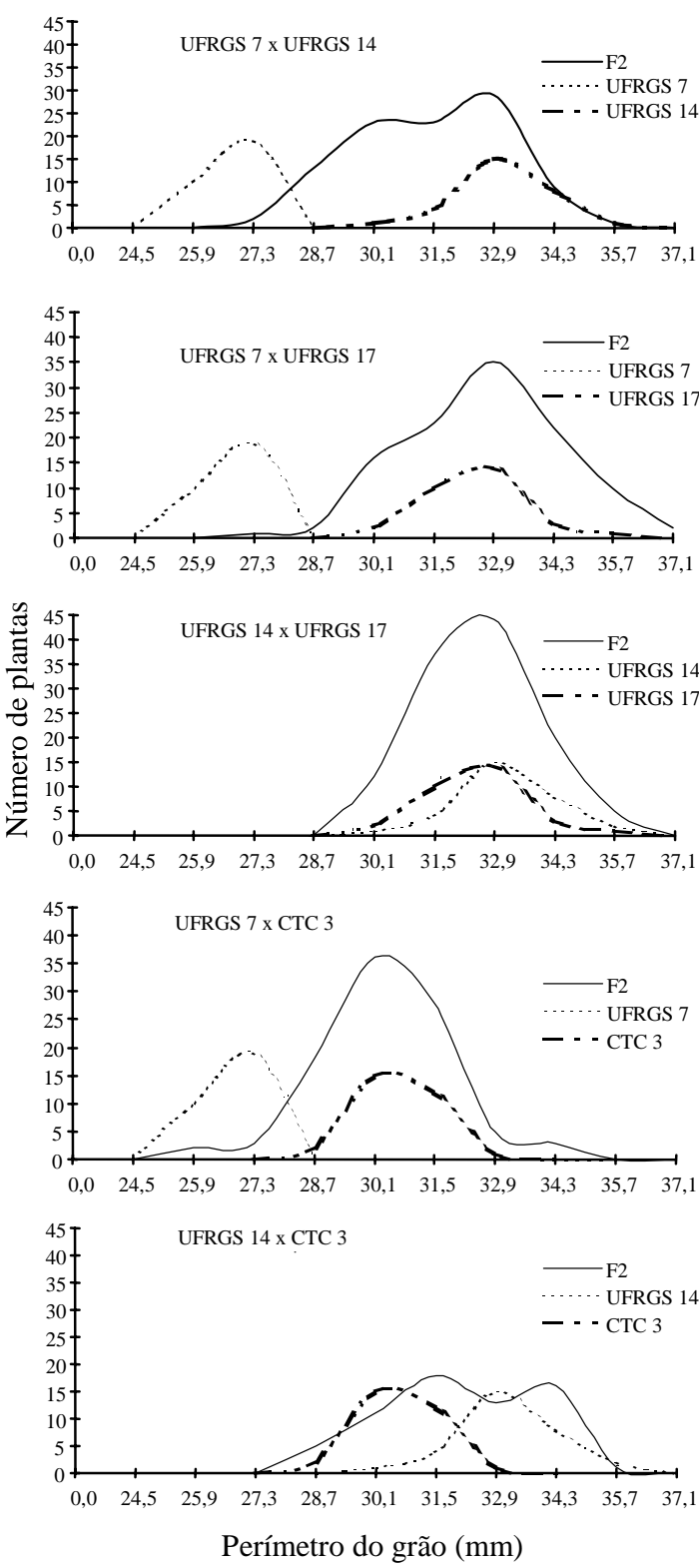

Figura 4. Distribuições de freqüência do caráter perímetro de grãos primários em duas gerações fixas $\left(\mathrm{P}_{1}\right.$ e $\left.\mathrm{P}_{2}\right)$, e uma geração segregante $\left(F_{2}\right)$, em cinco cruzamentos de aveia. EEA/UFRGS, 1998. 
Tabela 3. Médias das gerações $\mathrm{P}_{1}, \mathrm{P}_{2}, \mathrm{~F}_{1}, \mathrm{~F}_{2}$ e $\mathrm{F}_{3}$, número de plantas avaliadas em cada geração $(\mathrm{N})$, valores dos efeitos gênicos e do teste do qui-quadrado $\left(\chi^{2}\right)$ dos caracteres área, comprimento, largura e perímetro de grãos primários, obtidos de três cruzamentos de aveia. EEA/UFRGS, 1998.

\begin{tabular}{|c|c|c|c|c|c|c|}
\hline \multirow{2}{*}{$\begin{array}{l}\text { Geração e } \\
\text { efeito gênico }\end{array}$} & \multirow[t]{2}{*}{$\mathrm{N}$} & UFRGS 7 x UFRGS 14 & \multirow[t]{2}{*}{$\mathrm{N}$} & UFRGS 7 x UFRGS 17 & \multirow[t]{2}{*}{$\mathrm{N}$} & UFRGS 14 x UFRGS 17 \\
\hline & & $\left(\mathrm{P}_{2}\right) \quad\left(\mathrm{P}_{1}\right)$ & & $\left(\mathrm{P}_{2}\right)$ & & $\left(\mathrm{P}_{2}\right)$ \\
\hline & \multicolumn{6}{|c|}{ Área } \\
\hline $\mathrm{P}_{1}$ & 30 & $35,18 \pm 2,144$ & 30 & $32,34 \pm 1,475$ & 30 & $35,18 \pm 2,144$ \\
\hline $\mathrm{P}_{2}$ & 29 & $24,95 \pm 0,989$ & 29 & $24,95 \pm 0,989$ & 30 & $32,34 \pm 1,475$ \\
\hline $\mathrm{F}_{1}$ & - & - & 15 & $27,39 \pm 1,890$ & - & - \\
\hline $\mathrm{F}_{2}$ & 100 & $30,82 \pm 2,473$ & 112 & $30,18 \pm 2,440$ & 118 & $32,03 \pm 1,917$ \\
\hline $\mathrm{F}_{3}$ & 56 & $30,54 \pm 2,208$ & 62 & $28,43 \pm 1,981$ & 57 & $30,30 \pm 2,630$ \\
\hline [m] & & $30,081 \pm 0,207 *$ & & $29,054 \pm 0,206^{*}$ & & $33,251 \pm 0,225 *$ \\
\hline [a] & & $5,127 \pm 0,212 *$ & & $3,898 \pm 0,162 *$ & & $1,237 \pm 0,236^{*}$ \\
\hline [d] & & $1,525 \pm 0,655^{*}$ & & $0,402 \pm 0,460$ & & $-3,004 \pm 0,588^{*}$ \\
\hline [i] & & - & & $-0,335 \pm 0,231$ & & - \\
\hline $\mathrm{d} / \mathrm{a}$ & & 0,03 & & - & & $-2,4$ \\
\hline$\chi^{2}$ & & 0,0002 & & 0,1949 & & 0,1687 \\
\hline GL & & 1 & & 1 & & 1 \\
\hline \multirow[t]{2}{*}{$\mathrm{P}$} & & 0,99 & & 0,66 & & 0,68 \\
\hline & \multicolumn{6}{|c|}{ Comprimento } \\
\hline $\mathrm{P}_{1}$ & 30 & $14,41 \pm 0,502$ & 30 & $14,21 \pm 0,521$ & 30 & $14,41 \pm 0,502$ \\
\hline $\mathrm{P}_{2}$ & 29 & $11,41 \pm 0,227$ & 29 & $11,41 \pm 0,227$ & 30 & $14,21 \pm 0,521$ \\
\hline $\mathrm{F}_{1}$ & - & - & 15 & $13,62 \pm 0,635$ & - & $\begin{array}{c}-8,00 \\
-\end{array}$ \\
\hline $\mathrm{F}_{2}$ & 100 & $15,65 \pm 0,853$ & 112 & $14,34 \pm 0,892$ & 118 & $14,19 \pm 0,639$ \\
\hline $\mathrm{F}_{3}$ & 56 & $13,58 \pm 0,736$ & 62 & $13,85 \pm 0,859$ & 57 & $14,05 \pm 0,785$ \\
\hline [m] & & $12,937 \pm 0,049 *$ & & $12,921 \pm 0,052 *$ & & $14,277 \pm 0,063 *$ \\
\hline [a] & & $1,515 \pm 0,050 *$ & & $1,473 \pm 0,051^{*}$ & & $0,101 \pm 0,066^{*}$ \\
\hline [d] & & $1,577 \pm 0,195^{*}$ & & $1,741 \pm 0,140^{*}$ & & $-0,223 \pm 0,177$ \\
\hline [i] & & - & & $-0,059 \pm 0,046$ & & - \\
\hline $\mathrm{d} / \mathrm{a}$ & & 1,04 & & 1,2 & & - \\
\hline$\chi^{2}$ & & 0,0051 & & 0,1159 & & 0,0024 \\
\hline$\stackrel{\sim}{\mathrm{GL}}$ & & 1 & & 1 & & 1 \\
\hline \multirow[t]{2}{*}{$\mathrm{P}$} & & 0,94 & & 0,73 & & 0,96 \\
\hline & & & & Largura & & \\
\hline $\mathrm{P}_{1}$ & 30 & $3,206 \pm 0,161$ & 30 & $2,889 \pm 0,100$ & 30 & $3,206 \pm 0,161$ \\
\hline $\mathrm{P}_{2}$ & 29 & $2,608 \pm 0,117$ & 29 & $2,608 \pm 0,117$ & 30 & $2,889 \pm 0,100$ \\
\hline $\mathrm{F}_{1}$ & - & - & 15 & $2,563 \pm 0,103$ & - & - \\
\hline $\mathrm{F}_{2}$ & 100 & $2,821 \pm 0,223$ & 112 & $2,730 \pm 0,196$ & 118 & $2,950 \pm 0,164$ \\
\hline $\mathrm{F}_{3}$ & 56 & $2,866 \pm 0,202$ & 62 & $2,648 \pm 0,138$ & 57 & $2,812 \pm 0,168$ \\
\hline [m] & & $2,907 \pm 0,018^{*}$ & & $2,762 \pm 0,014 *$ & & $3,003 \pm 0,016^{*}$ \\
\hline [a] & & $0,299 \pm 0,018^{*}$ & & $0,138 \pm 0,014^{*}$ & & $0,138 \pm 0,017^{*}$ \\
\hline [d] & & $-0,172 \pm 0,050^{*}$ & & $-0,152 \pm 0,028 *$ & & $-0,173 \pm 0,046^{*}$ \\
\hline [i] & & - & & $-0,013 \pm 0,015$ & & - \\
\hline $\mathrm{d} / \mathrm{a}$ & & $-0,57$ & & $-1,10$ & & $-1,25$ \\
\hline$\chi^{2}$ & & 0,0000001 & & 0,0036 & & 0,0093 \\
\hline$\stackrel{n}{\mathrm{GL}}$ & & 1 & & 1 & & 1 \\
\hline $\mathrm{P}$ & & 0,99 & & 0,95 & & 0,92 \\
\hline
\end{tabular}

Continua... 
Tabela 3. Continuação.

\begin{tabular}{|c|c|c|c|c|c|c|}
\hline \multirow{3}{*}{$\begin{array}{l}\text { Geração e } \\
\text { efeito gênico }\end{array}$} & $\mathrm{N}$ & UFRGS 7 x UFRGS 14 & $\mathrm{~N}$ & UFRGS 7 x UFRGS 17 & $\mathrm{~N}$ & UFRGS 14 x UFRGS 17 \\
\hline & & $\left(\mathrm{P}_{2}\right) \quad\left(\mathrm{P}_{1}\right)$ & & $\left(\mathrm{P}_{2}\right)$ & & $\left(\mathrm{P}_{2}\right) \quad\left(\mathrm{P}_{1}\right)$ \\
\hline & \multicolumn{6}{|c|}{ Perímetro } \\
\hline $\mathrm{P}_{1}$ & 30 & $32,48 \pm 1,090$ & 30 & $31,84 \pm 1,111$ & 30 & $32,48 \pm 1,090$ \\
\hline $\mathrm{P}_{2}$ & 29 & $26,05 \pm 0,462$ & 29 & $26,05 \pm 0,462$ & 30 & $31,84 \pm 1,111$ \\
\hline $\mathrm{F}_{1}$ & - & - & 15 & $30,44 \pm 1,346$ & - & - \\
\hline $\mathrm{F}_{2}$ & 100 & $30,68 \pm 1,760$ & 112 & $32,02 \pm 1,836$ & 118 & $31,82 \pm 1,320$ \\
\hline $\mathrm{F}_{3}$ & 56 & $30,58 \pm 1,510(56)$ & 62 & $31,03 \pm 1,781$ & 57 & $31,49 \pm 1,696$ \\
\hline$[\mathrm{m}]$ & & $29,319 \pm 0,106^{*}$ & & $29,199 \pm 0,115^{*}$ & & $32,076 \pm 0,136^{*}$ \\
\hline [a] & & $3,255 \pm 0,107 *$ & & $3,080 \pm 0,109 *$ & & $0,323 \pm 0,142 *$ \\
\hline [d] & & $3,018 \pm 0,407 *$ & & $3,446 \pm 0,300 *$ & & $-0,630 \pm 0,373$ \\
\hline [i] & & - & & $-0,128 \pm 0,100$ & & - \\
\hline $\mathrm{d} / \mathrm{a}$ & & 0,93 & & 1,12 & & - \\
\hline$\chi^{2}$ & & 0,0094 & & 0,2218 & & 0,0062 \\
\hline GL & & 1 & & 1 & & 1 \\
\hline $\mathrm{P}$ & & 0,92 & & 0,64 & & 0,94 \\
\hline
\end{tabular}

${ }^{(1)} \mathrm{GL}$ : graus de liberdade para o teste do qui-quadrado; P: probabilidade pelo teste do qui-quadrado. *Significativo a $5 \%$ de probabilidade pelo teste t.

Tabela 4. Valores de variância fenotípica (VP), genética (VG) e de ambiente (VE), herdabilidade no sentido amplo $\left(\mathrm{h}^{2}{ }_{\mathrm{a}}\right.$ ) e pai-progênie (b) dos caracteres área, comprimento, largura e perímetro de grãos primários em cinco cruzamentos de aveia. EEA/UFRGS, 1997 e 1998.

\begin{tabular}{lccccc}
\hline Cruzamento & VP & VG & VE & $\mathrm{h}_{\mathrm{a}}^{2}$ & $\mathrm{~b}$ \\
\hline & & & Área & & \\
UFRGS 7 x UFRGS 14 & 6,115 & 3,332 & 2,782 & 54,5 & 47,0 \\
UFRGS 7 x UFRGS 17 & 5,952 & 4,375 & 1,577 & 73,5 & 40,5 \\
UFRGS 14 x UFRGS 17 & 3,673 & 0,292 & 3,381 & 8,0 & 52,5 \\
UFRGS 7 x CTC 3 & 4,991 & 3,782 & 1,210 & 75,8 & - \\
UFRGS 14 x CTC 3 & 5,686 & 2,673 & 3,013 & 47,0 & - \\
\hline & & \multicolumn{5}{c}{ Comprimento } \\
UFRGS 7 x UFRGS 14 & 0,728 & 0,576 & 0,152 & 79,1 & 45,8 \\
UFRGS 7 x UFRGS 17 & 0,795 & 0,634 & 0,161 & 79,7 & 53,3 \\
UFRGS 14 x UFRGS 17 & 0,409 & 0,147 & 0,262 & 36,0 & 54,1 \\
UFRGS 7 x CTC 3 & 0,660 & 0,567 & 0,093 & 85,8 & - \\
UFRGS 14 x CTC 3 & 0,544 & 0,351 & 0,194 & 64,4 & \\
\hline & & \multicolumn{5}{c}{ Largura } & 53,3 \\
UFRGS 7 x UFRGS 14 & 0,049 & 0,030 & 0,019 & 59,9 & 48,7 \\
UFRGS 7 x UFRGS 17 & 0,038 & 0,026 & 0,012 & 69,1 & - \\
UFRGS 14 x UFRGS 17 & 0,027 & 0,009 & 0,018 & 33,1 & - \\
UFRGS 7 x CTC 3 & 0,036 & 0,024 & 0,012 & 65,4 & \\
UFRGS 14 x CTC 3 & 0,028 & 0,010 & 0,019 & 34,3 & 45,6 \\
\hline & & Perímetro & \\
UFRGS 7 x UFRGS 14 & 3,096 & 2,395 & 0,701 & 77,3 & 55,6 \\
UFRGS 7 x UFRGS 17 & 3,370 & 2,645 & 0,725 & 78,5 & - \\
UFRGS 14 x UFRGS 17 & 1,742 & 0,529 & 1,212 & 30,4 & - \\
UFRGS 7 x CTC 3 & 2,701 & 2,312 & 0,389 & 85,6 & \\
UFRGS 14 x CTC 3 & 2,887 & 2,011 & 0,876 & 69,6 &
\end{tabular}


ção proveniente do cruzamento entre UFRGS 7 e CTC 3 é a população onde o progresso genético pode ser obtido mais facilmente com seleção em $\mathrm{F}_{2}$ quanto a todas as características analisadas, uma vez que apresentou os maiores valores em relação às outras populações estudadas. Contudo, por serem caracteres quantitativos, sujeitos a um maior efeito do ambiente, seleção em gerações precoces deve ser feita com cautela, isto é, com pressão de seleção reduzida.

Os valores estimados de herdabilidade pai-progênie foram moderados nos três cruzamentos avaliados, UFRGS 7 x UFRGS 14, UFRGS 7 x UFRGS 17 e UFRGS 14 x UFRGS 17, para as quatro características (Tabela 4). Na média, a herdabilidade paiprogênie foi de $47 \%$ para área, $51 \%$ para comprimento, $48 \%$ para largura e $52 \%$ para perímetro. Os valores próximos para comprimento e largura contrariam os obtidos por Murphy \& Frey (1962) quanto a essas duas características, onde o comprimento apresentou valor de herdabilidade superior ao de largura, pelo fato de a largura sofrer maior influência do ambiente durante o desenvolvimento do grão.

De maneira geral, os valores médios de herdabilidade pai-progênie foram menores que no sentido amplo em todas as características, o que era esperado, uma vez que a herdabilidade pai-progênie, que mais se aproxima do sentido restrito, representaria somente a variância de aditividade, descontada a variância de outros efeitos gênicos e a do ambiente. Exceção ocorreu no cruzamento UFRGS 14 x UFRGS 17, onde a herdabilidade pai-progênie foi superior à herdabilidade no sentido amplo nas quatro características avaliadas. Isso pode ter ocorrido devido às diferentes gerações utilizadas nas estimativas; para o cálculo da herdabilidade no sentido amplo, foram utilizados os pais e $F_{2}$ semeados em 1998, e para pai-progênie, as $F_{2}$ de 1997 e suas respectivas progênies $F_{3}$ colocadas no campo em 1998.

O cruzamento entre os genótipos de maior área, comprimento, largura e perímetro de grãos (UFRGS 14 e UFRGS 17) apresentou valores de herdabilidade pai-progênie similares aos dos demais relativos a essas características; aliado a isto, a ausência de segregação transgressiva e a similaridade entre as médias das progênies $F_{2}$ indicam que o melhoramento deve buscar alelos favoráveis de consti- tuição diferenciada em genitores divergentes para continuar tendo progresso no incremento dessas características em aveia.

\section{Conclusões}

1. Existe variação genética significativa em populações segregantes $F_{2}$ nos cruzamentos de aveia avaliados quanto a área, comprimento, largura e perímetro de grãos primários, sendo significativos os efeitos gênicos de aditividade e de dominância.

2. As herdabilidades das características morfológicas de grão analisadas são moderadas, e variam de acordo com o cruzamento.

\section{Referências}

ALLARD, R. W. Principles of plant breeding. 3. ed. New York : J. Wiley, 1960. 485 p.

BACKES, G.; GRANER, A.; FOROUGUI-WEHR, B. Localization of quantitative trait loci (QTL) for agronomic important characters by the use of a RFLP map in barley (Hordeum vulgare L.). Theoretical and Applied Genetics, Berlin, v. 90, p. 294-302, 1995.

BORÉM, A. Melhoramento de plantas. Viçosa, MG : UFV, 1997. 547 p.

BOTHONA, C. R. A. Qualidade do grão de aveia: identificação de características físicas associadas ao rendimento industrial e regiões genômicas. Porto Alegre : UFRGS, 1997. 98 p. Dissertação de Mestrado.

BOTHONA, C. R. A.; MILACH, S. C. K.; THOMÉ, G. H.; CABRAL, C. B.; TISIAN, L. M.; MELLOS, G. O. Critérios para avaliação da morfologia do grão de aveia para o melhoramento genético da qualidade física. Ciência Rural, Santa Maria, v. 29, n. 4, p. 613-618, 1999.

FEDERIZZI, L. C.; ACAUAN, L. R.; CARVALHO, F. I. F. Variabilidade fenotípica de diferentes caracteres da panícula em aveia (Avena sativa L.). Pesquisa Agropecuária Brasileira, Brasília, v. 30, n. 2, p. 223-229, fev. 1995.

FEDERIZZI, L. C.; CARVALHO, F. I. F.; BARBOSA NETO, J. F. Programas de melhoramento genético de aveia no sul do Brasil: possibilidades e perspectivas. In: REUNIÃO ANUAL CONJUNTA DE PESQUISA DE AVEIA, 11., 1991, Passo Fundo. Anais... Passo Fundo : Universidade de Passo Fundo, 1991. p. 3-11. 
FEDERIZZI, L. C.; PACHECO, M. T.; MILACH, S. C. K. Ensaio de cultivares recomendadas de aveia: EEA/UFRGS, Eldorado do Sul, 1995. In: REUNIÃO DA COMISSÃO SUL-BRASILEIRA DE PESQUISA DA AVEIA, 16. 1996, Florianópolis. Anais... Florianópolis : UFSC, 1996a. p. 76-78.

FEDERIZZI, L. C.; PACHECO, M. T.; MILACH, S. C. K. Ensaio sul-brasileiro de linhagens de aveia: EEA/UFRGS, Eldorado do Sul, 1995. In: REUNIÃO DA COMISSÃO SUL-BRASILEIRA DE PESQUISA DA AVEIA, 16. 1996, Florianópolis. Anais... Florianópolis : UFSC, 1996b. p. 74-75.

FLOSS, E. L.; SCHULZ, J.; TRENTIN, E. A. Qualidade industrial de grãos de cultivares de aveia em Passo Fundo, 1994. In: REUNIÃO DA COMISSÃO SUL-BRASILEIRA DE PESQUISA DA AVEIA, 16., 1996, Florianópolis. Anais... Florianópolis : UFSC, 1996. p. $143-$ 148.

GODOY, R. R.; JORGE, L. A. C.; CRESTANA, S. Determinação do comprimento e largura de grãos de aveia através de processamento de imagens. In: REUNIÃO DA COMISSÃO SUL-BRASILEIRA DE PESQUISA DA AVEIA, 14., 1994, Porto Alegre. Anais... Porto Alegre : UFRGS, 1994. p. 389-392.

LERNSTEN, N. R. Morphology and anatomy of the wheat plant. In: WHEAT and wheat improvement. Madison : Crop Science Society America, 1987. p. 33-76.

MARSHALL, H. G.; SHANER, G. E. Genetics and inheritance in oat. In: MARSHALL, H. G.; SORRELS, M. E. (Ed.). Oat science and technology. Madison : Crop Science Society America, 1992. p. 756-775.
MATHER, S. K.; JINKS, J. L. Biometrical genetics. 3. ed. Cambridge : Cambridge University Press, 1982. 396 p.

MILACH, S. C. K.; FEDERIZZI, L. C.; THOMÉ, G. C. H. Características de grãos das cultivares recomendadas de aveia. In: REUNIÃO DA COMISSÃO SUL-BRASILEIRADE PESQUISA DAAVEIA, 16., 1996, Florianópolis. Anais... Florianópolis : UFSC, 1996. p. 45-46.

MOREnO, J. A. Clima do Rio Grande do Sul. Porto Alegre : Secretaria da Agricultura, 1961. 38 p.

MURPHY, C. F.; FREY, K. J. Inheritance and heritability of seed weight and its components in oats. Crop Science, Madison, v. 2, p. 509-512, 1962.

PIXLEY, K. V.; FREY, K. J. Inheritance of test weight and its relationship with grain yield of oat. Crop Science, Madison, v. 31, p. 36-40, 1991.

PRASAD, K.; SEETHARAMAN, R. Inheritance of grain size and its interrelationship in rice. Indian Journal of Genetics, Hazaribag, v. 51, n. 3, p. 352-356, 1991.

SAPIRSTEIN, H. D. Variety identification by digital image analysis. In: WRIGLEY, C. W. (Ed.). Identification of food-grain varieties. St. Paul : American Association of Cereal Chemistry, 1995. p. 91-130.

SHATADAL, P.; JAYAS, D. S.; BULLEY, N. R. Digital image analysis for software separation and classification of touching grains: II. Classification. ASAE Transactions, St Joseph, v. 38, n. 2, p. 645-649, 1995.

STEEL, R. D. G.; TORRIE, J. L. Principles and procedures of statistics. New York : MacGraw-Hill, 1980. $418 \mathrm{p}$. 